А. Д. Горбань, О. И. Карманова

\title{
ТЕКСТЫ-РАССУЖДЕНИЯ. РИТОРИКО-СТИЛИСТИЧЕСКИЙ АСПЕКТ (НА МАТЕРИАЛЕ АНГЛИЙСКОГО ЯЗЫКА)
}

Горбань О. Д., Карманова О. І. Тексти-роздуми. Риторико-стилістичний аспект (на матеріалі англійської мови).

Виявляються основні параметри текстів-роздумів, аналізуються риторикостилістичні аспекти їх утворення.

Ключові слова: тексти-роздуми, композиція, логіко-структурні особливості, типологія, есе.

Горбань А. Д., Карманова Е. И. Тексты-рассуждения. Риторико-стилистический аспект (на материале английского языка).

Выявляются основные параметры текстов-рассуждений, анализируются риторико-стилистические аспекты их создания.

Ключевые слова: тексты-рассуждения, композиция, логико-структурные особенности, типология, эссе.

Horban A. D., Karmanova O. I. Reasoning Texts. Ritorico-stylistical aspects (the example of English).

( А. Д. Горбань, Е. И. Карманова, 2014. - 172 - 
Ritorico-stylistical aspects of reasoning texts composition being analyzed and delineated their main text-forming parameters. Text typology problem on the level of speech composition being investigated, taking into account lingvo-stylistical factors.

Key words: reasoning texts, composition, logic-structural peculiarities, topology, essay.

Цель статьи - исследовать особенности лингвистической организации текстов-рассуждений на раннем этапе их литературного оформления, выявить роль риторических средств в процессе оформления этих текстов. Композиционно-речевая форма «рассуждение» рассматривается не только как речевая единица для логического оформления содержания, а как текстовое единство, имеющее свои стилистические варианты, которые оказывают влияние на грамматические и синтаксические особенности текстов-рассуждений.

Изучение лингвостилистической организации текстоврассуждений, к которым мы относим жанры массой прозы английской литературы второй половины XVII века - эссе Т. Брауна (1605-1628), А. Каули (1618-1667), Дж. Тейлора (1613-1667), связано с одной из самых актуальных в современной лингвистической науке проблем изучением композиционно-речевых форм. Научный подход к изучению композиционно-речевой формы «рассуждение» основывается, как правило, на анализе механизма логических процессов - заключений ума [1-6]. Важный для изучения данной лингвистической проблемы логико-мыслительный подход может быть лишь началом исследования, цель которого - выявление всего комплекса лингвистических особенностей этого речевого явления. Следует отметить, что специфика тестов-рассуждений в художественной литературе состоит в том, что здесь нет чётких, как в научном или ораторском сочинении, строгих форм построения речи. Отсюда трудности изучения «нестандартной» композиции подобных произведений.

Аргументативное эссе всегда состоит из отдельных частей, которые зачастую слабо стыкуются друг с другом. Трудность состоит в том, что нет возможности органически конструировать аргумент, поскольку основной его целью является суждение, а не опыт. Это суждение состоит из различного вида умственных операций, которые в итоге трудно привести в полное соответствие. Писатель должен сформулировать свою собственную позицию наряду с тем, что часто приходится опровергать позицию оппонента. 
Все эссе состоят из одного рассуждения, которое, однако, строится по усложнённой модели, не сводимой к логико-понятийной схеме. В эссе как промежуточном жанре, принадлежащем одновременно сфере науки и художественной литературы, широко использован и механизм речевого оформления мысли, заимствованный из науки, и образные средства её воплощения, временами сближаясь с поэзией (как эссе Тейлора, медитации Трахерна). В текстах-рассуждениях второй половины XVII в. главным фактором текстообразования становится не заданный рассудком тип рационально-логической аргументации, а риторическая аргументация стиля, его выразительность. Стиль здесь не является чемто «чисто формальным» по отношению к идеям, а является неотъемлемым критерием текста, ведь глубина мысли может быть утрачена, если не выражена соответствующая стилистика.

Спецификой текстов-рассуждений является насыщенность стиля, фигурами мысли и фигурами речи. В античной классификации фигура мысли не меняются от пересказа другими словами. Они могут быть обращены к предмету речи (уточнить мысль, чувство, образ), к публику, к сопернику. Фигуры речи - фигуры, которые разрушаются от пересказа другими словами. Следует заметить, что для одних текстоврассуждений более характерны фигуры речи, для других фигура мысли. В разработанных в Англии XVII века теоретических проблемах риторики эти формы организации речи были в центре внимания.

Рассмотрим, как Д. Тейлор использует фигуры речи эссе “Тhе Rule and Exercises of Holy Dying” и, в частности, в первом абзаце первой части, которая называется "Consideration of the Vanity and Shortness of Man's Life" [7].

A man is a Bubble, said the Greek proverb; which Lucian represents with advantages and its proper circumstances, to this purpose saying, that all the world is a storm, and men rise up in their several generations, like bubbles descending a jove pluvio, from god and dew of heaven, from a tear a drop of man, from nature and providence [7, p. 441].

Эссе начинается с тезиса или заключительной части, представленной в виде греческой пословицы A man is a bubble. Вся последующая часть - это главная предпосылка, поддерживающая тезис. Автор использует широкий спектр фигур речи для образной реализации мысли, заложенной в тезисной части.

Логическое и эмоциональное отражение действительности в данном тексте - рассуждении настолько взаимосвязаны друг с другом, ๑ А. Д. Горбань, Е. И. Карманова, 2014. - 174 - 
что невозможно определить, какой из этих показателей главенствует. Эмоциональное и рациональное, здесь сливаются в единый процесс познания окружающего мира, а убедительность изложения достигается не только строгой логичностью аргументации, так и особым выбором языковых средств выражения последней, что заметно отлично от текстов-рассуждений научного плана. Композиция держится не только на риторическом синтаксисе, но и на образах - концептах (человекпузырёк воздуха). Главное в прозе Тейлора - не религиозно-этический смысл, а эстетически тонкие образы. При построении периода, автор широко использует лексическую анафору: ... from god and dew of heaven, from a tear and drop of man, from nature and providence [7, p. 441].

Дополнительную экспрессивную нагрузку здесь несёт аллитерация: death and dorkness; chances of a child; sleeply servant.

Одним из условий, способствующих реализации экспрессивного потенциала слова, является «удвоение» того или иного квалификативного компонента его семантики. Компонент интенсивности активно притягивает семантические элементы, дублирующие его содержание, интенсификант сочетается со словом - усилителем, частично дублирующим интенсивный компонент его семантики.

Стремясь подчеркнуть роль каждого из однородных членов на протяжении всего абзаца, автор употребляет полисиндетон:

...And suddenly disappear, and give their place to otheres...

...it many be untill seven years of vanity be expired, and then peradventure the sun shines not upon their heards, and they fall into the shades below...

В данном отрывке мы находим упорядоченное использование параллелизма и антитезы, построенных в основном на синтаксическом повторе:

...to preserve a man alive in the midst of so many chances and hostilities, is as great a miracle, as to reate him; to preserve him from rushing into nothing, and at first to draw him up.

...To be born that they might be able to die;

... others float up and down... but that they made their parents a little glad, and very sorrowful...

Параллелизм представляет собой устойчивую фигуру речи в тексте-рассуждении, в сочетании с антитезой он превращается в типовой приём организации всего высказывания. Д. Тейлор использует параллелизм в целях логического противопоставления и сопоставления, 
а также в целях уточнения и развития мысли в ходе рассуждения, аргументации. Синтаксический параллелизм в тексте-рассуждении помогает автору так оформить мысль, чтобы подчеркнуть логичность высказывания и процесс движения самой мысли.

Самой распространённой фигурой речи в текстах-рассуждениях является градация. Так у Д. Тейлора нарастание идёт в течение всего хода рассуждения. Каждое новое высказывание заключает в себе усиливающееся смысловое или эмоционально-экспрессивное значение.

Экспрессивную функцию в текстах-рассуждениях зачастую выполняют антонимические сравнения.

У Д. Тейлора:

...A little glad and very sorrowful [7, p. 440].

У Темпля:

The power of music are either felt or know by all men, and are allowed to work strangely upon the mind and the bode, the passions and the blood, to rise joy and grief, pleasure and pain [8, p. 547].

Можно сделать вывод, что распространёнными типами риторической организации текста-рассуждения являются такие фигуры речи, как анафора, антитезы, градация, полисиндетон и такие фигуры мысли, как предвосхищение, предупреждение, предположение. Фигуры мысли создают эффект движения сознания, а фигуры речи придают особую выразительность и акцентность этому процессу.

Эссе-рассуждение начинается как бы с заключения, с итоговой мысли, раскрытие глубинного, философского смысла которой и составляет основную тему рассуждения. В качестве примера рассмотрим эссе А. Каули "Of solitude", которое начинается с итоговой мысли, рассуждения Цицерона о том, что человек наименее одинок тогда, когда он одинок: Nunquam minus solus quam solus is now became a very vulgar saying. Every man, and almost every boy, for these seventeen hundred years had it in his mouth [9, p. 468].

Далее автор рассуждая об одиночестве, анализирует разные его мотивы. Наиболее частым приёмом аргументации в рассуждениях А. Каули является цитирование. Далее в эссе мы читаем: This would be no wonder, if it were as truly as its colorably and wittily said by Mousier de Montaigne, that ambition itself might teach us to love solitude; There's nothing does so much hate to have companious [9, p. 468].

Данный участок текста представляет собой энтимему, состоящую из заключения и главной предпосылки, поддерживающей это заключение.

(ㄱ А. Д. Горбань, Е. И. Карманова, 2014. - 176 - 
Наряду с цитацией автор использует для аргументации и аналогию: ...This true, it loves to have its elbows free, it detests to have company on either side, but it delights above all things in a traint behind [9, p. 468].

Далее следует новая энтимема, основанная на других предпосылках, но поддерживающая ту же заключительную мысль, которая была высказана в начале рассуждения: It is very fantastical and contradictory in human nature, that men should love themselves above all the rest of the world, and yet never endure to be with themselves. When they are in love with a mistress, all other persons are importunate and burdensome to them [9, p. 468].

В качестве аргумента того, что человеку всё-таки свойственно стремление к одиночеству, несмотря даже на самую сильную привязанность, А. Каули опять использует цитацию-аргумент. Очевидно, что в начальной части эссе исчерпывается логическая структура текста, но не исчерпывается его образная правда, всегда за заключением или итоговой мыслью следуют части, выражающие новое понимание этой мысли, причём продвижение мысли в текстерассуждении осуществляется в направлении более живой образной реализации. Д. Коппершмидт говорит о «прядях» аргументации (strands of argumentation) и понимает под этим частичные аргументации. По его мнению существует микроструктурная и макроструктурная аргументация [10, с. 98]. Именно этот процесс и осуществляется в текстах-рассуждениях. Каждая новая энтимема, каждый новый поворот мысли освещает тот же момент с разных уровней. Обращают на себя внимание сравнения, действующие как вид быстрого доказательства:

They may like petty thieves, cheat us prhaps, pick our pockets...

...Like robbers they use to strip and bind, or murder us... [9, p. 469].

Если посмотреть на весь текст в целом, то осуществляется отмечаемый М. Кроллом [11] характерный для барочной прозы принцип спирального движения. Союзы, соединяющие периоды (в большинстве случаев это but, and, nor), не имеют силы логического плюса, а как бы соединяют два усилия воображения, постигающего ту же идею. Рассуждение развивается от конкретного к абстрактному. Это не доказательство, осуществляется сдвиг мысли к новому предмету, теме, буквальному или метафорическому утверждению. Истина как бы рассеяна по всему тексту. Каждый новый периодоткровение, а каждая сентенция претендует быть выводом. Отличительная черта данного текста-рассуждения в том, что 
логически он состоит из расширенной энтимемы, причём энтимемы не доказательной (как в «Аналитике» Аристотеля), а энтимемы правдоподобной (по «Топике» Боэция), которая в свою очередь, содержит несколько энтимем, основанных на разных предпосылках, но поддерживающих один и тот же тезис. Подобное строение разрушает формальную логическую структуру, поскольку связи между энтимемами не всегда явные. Поскольку рассуждение начинается с заключения или тезиса, то все последующие части, или энтимемы, будут представлять собой своеобразный антитезис.

Этот антитезис является обязательной частью аргументативного рассуждения. В текстах-рассуждениях, таким образом, важен сам процесс мысли, не только логическая, но и лингвистическая проявленность.

Энтимемы - как бы вехи развития этого процесса. Если убрать одну или несколько этих вех, то всё рухнет, так как важен не итог, а сам процесс мысли.

Тезис и антитезис облекаются в образную, хотя и обобщённую форму. М. Кролл полагает, что движение периода в подобных текстах можно описать как серию обратных движений, возникающих в период логической паузы или временной остановки, и сравнивая подобное движение с проблесковым светом маяка или с блеском граней бриллианта [10, с. 1096].

В композиции текстов-рассуждений тезис и антитезис постепенно приходят к синтезу, который представляет собой не какие-то материальные заключения, а своеобразное постижение текста, когда мы доходим до его конца.

Одним из наиболее эффективных средств реализации модальности в текстах-рассуждениях является дистантный повтор. Это и понятно, поскольку повторяется лишь то, что с авторской точки зрения является важным, и уже поэтому повтор несёт определённую авторскую оценку. Так, у Гланвилла в «Эссе относительно проповеди» при помощи дистантного повтора обыгрывается слово plain и его производные. По ходу текста мы встречаем:

Plainness is a character of great latitude and stands in opposition ...

The Preacher should use plain words. Preaching should be plain, in opposition to deep and musterious notions.

Plainness may be opposed to effected rhetoric.

Plainness is for ever the best eloquence.

๑ А. Д. Горбань, Е. И. Карманова, 2014. - 178 - 
Plainness of preaching implies also the avoiding of ... [12, p. 357]

Таким образом, дистантный повтор, как одна из наиболее эффективных фигур речи, выполняет в тексте важную роль. Прежде всего влияет на композицию текста-рассуждения, поскольку почти всегда представляет собой силлогизм, составляющий главную посылку энтимемы, и тем самым способствует ходу рассуждения. Очевидно также и то, что подобный приём увеличивает экспрессивность слов.

Сентенции у Гланвилла представляют собой «сгустки мысли», в основе которых лежит прагматический парадокс, как в случае plainness-eloquence.

В тезаурусе современников эти слова противоположны по своему значению, а Гланвилл не только делает их синонимами, но и концептуально заостряет сопряжённость их смыслов, резко повышая при этом их экспрессивность.

Экспрессивную функцию в текстах-рассуждениях зачастую выполняют антонимические сравнения.

У Тейлора:

... a little glad and very sorrowful [7, p.440].

У Темпля:

The power of music are either felt or known by all men, and are allowed to work strangely upon the mind and the body, the passions and the blood, to raise joy and grief, to give pleasure and pain [8, p.547].

Более интенсивное и концентрированное использование фигур мысли было характерным для эссе-рассуждений полемического характера. Так, Драйден в эссе "A detence of an Essay of Dramatic poesy” широко использует фигуры мысли, которые обращены к сопернику, такие как:

1) протасис (предположение - то, что ты сам и назвал, и отвергнул): ... for it all the enemies of verse will confess as much, I shall not need to prove that it is natural [13, p. 606];

2) апокрисис (дать ответ на вопрос, который сам и задал): As for the question as the states it, whether rhyme be nearest the nature of what it represents, I wonder he should think me so ridiculous as to dispute whether prose or verse be rearest to ordinary conversation [13, p. 606];

3) антгипофору (предвосхищение в том, чтобы сказать, что сказал бы противник): It still remains for him to prove his inference-that, since verse is granted to be more remote than prose from ordinary conversation, therefore no serious plays ought to be write in verse: and when he clearly

- 179 - О А. Д. Горбань, Е. И. Карманова, 2014. 
makes that good, I will acknowledge his victory as absolute as he can desire it [13, p. 606].

Подводя итог, можно сделать вывод, что распространённым типом риторической организации текста-рассуждения являются такие фигуры речи, как анафора, антитеза, градация, полисиндетон, и такие фигуры речи, как предвосхищение, предупреждение, предположение. Причём, в некоторых текстах-рассуждениях с ослабленной, нежёсткой композицией коэффициент риторических фигур мысли намного превышает уровень использования фигур речи. Фигуры мысли создают эффект движения сознания, а фигуры речи придают особую выразительность и акцентность этому процессу.

Очевидно, что на коммуникативно-логическую структуру текстарассуждения оказывает непосредственное влияние фактор прагматической установки на адресата. Анализ текстов обнаруживает, что чем больше отдалён автор от адресата, тем больше текст чреват риторикой, тем больше используется общих, доходчивых, сильнодействующих ораторских приёмов оформления мысли. Убедительность рассуждения зависит от правильности выбранного способа распределения семантической информации относительно экстралингвистических факторов данной ситуации общения. Следовательно, процесс рассуждения невозможен без учёта прагматических факторов. Их единство и образует сущность рассуждения как речемыслительного процесса. В прямой зависимости от прагматической установки находится вся структура рассуждения: характер аргументации, доказательства, аналогия и вся система экспрессивно-стилистических приёмов и их динамическое взаимодействие.

Таким образом, анализ процессов текстообразования в английской прозе второй половины XVII века обнаруживает, что «рассуждение» являлось не одним из превосходящих элементов композиционно-речевой структуры нефикционального типа текстов, а было единственной основой цельнооформленного текста разных жанров - эссе, проповедей, медитаций. Называть ли все эти сочинения словом «эссе», можно спорить, но именно эту «речемыслительную» общность отрицать нельзя, что следует из анализа лингвостилистической организации текстов разных жанров. 


\section{Литература}

1. Мордвинов А. Б. Рассуждение как тип текста / А. Б. Мордвинов // Вестник Моск. ун-та : Филология. - 1976. - №3.

2. Мордвинов А. Б. Некоторые особенности темпорального строения текста, представляющего рассуждение / А. Б. Мордвинов // Функциональные стили и преподавание иностранных языков. - М., 1982.

3. Нечаева О. А. Функционально-смысловые типы речи (описание, повествование, рассуждение) : дис. ... д-ра филол. наук / О. А. Нечаева. - М., 1975.

4. Черемисина О. Н. Типы и функции композиционно-речевой формы «рассуждение» в современной английской прозе : дис. ... канд. филол. наук / О. Н. Черемисина. - М., 1986.

5. Панфилов В. 3. Взаимодействие языка и мышления / В. 3. Панфилов. - М., 1971.

6. Miller G. A. Plan and structure of behavior / G. A. Miller, E. Galanter, K. H. Pribram. - L., 1960.

7. Teylor J. The rule and exercises of holy dying / J. Teylor // Seventeenth Century Prose and Poetry. - N.Y. ; San Diego ; San Francisco, 1982.

8. Temple W. Of Poetry / W. Temple // Seventeenth Century Prose and Poetry. - N. Y. ; San Diego ; Chicago ; San Francisco, 1982.

9. Cowley A. Of solitude / A. Cowley // Seventeenth Century Prose and Poetry. - N. Y. ; San Diego ; Chicago ; San Francisco, 1982.

10. Koppershmidt J. Rhetorica Aubstage zur Theorie / J. Koppershmidt // Geshichte und Praxis. - Hildesheim, 1985. - Vol. XII.

11. Croll M. W. The Baroque Style in Prose / M. W. Croll // Seventeenth Century Prose and Poetry. - N. Y. ; San Diego ; Chicago ; San Francisco, 1982.

12. Glanvill J. An Essay concerning preaching / J. Glanvill // Literary Criticism of Seventeenth-Century England. - N.-Y. : Alted. A. KNOPF, 1967 - P. 353-358.

13. Dryden J. A defence of an Essay of Dramatic Poesy / J. Dryden // SeventeenthCentury Prose and Poetry. - N.-Y. ; San Diego ; Chicago, Sel. And ed. By A. M. Witherspoon, 1982. - P. 605-613.

Стаття надійшла до редакиії 12.10.2014 p. 